\title{
Safety Sign, Symbols And Road Markings Of 'Planned Residential Areas With Adjacent Highways' Of Dhaka City: Focusing Pedestrian Safety
}

\author{
${ }^{1}$ Iftekhar Rahman, ${ }^{2} \mathrm{Md}$. Mostafizur Rahman,${ }^{3} \mathrm{M}$. Ahmed \\ ${ }^{1,2}$ Assistant Professor, Department of Architecture, Shahjalal University of Science and Technology, Sylhet- \\ 3114, Bangladesh. \\ ${ }^{3}$ Professor, Department of Civil and Environmental Engineering, Shahjalal University of Science \& Technology, \\ Sylhet-3114, Bangladesh,
}

\begin{abstract}
Demand of safety roads is a movement now-a-days, as numbers of accidents are increasing day by day, because of increasing number of vehicles and side by side, increasing of unskilled drivers to fulfill the necessary demand of the increased motorization. Beside all these, lack of proper safety signs, symbols and road markings are some of the major reasons behind these unwanted accidents

Studies are required to investigate the present situation of these signs and symbols in terms of public safety. For this purpose this study will be focused on the present context of safety signs, symbols and road markings in some of the planned residential areas of Dhaka city, with adjacent highway. The focus of this paper is to see the present situation of safety signs, symbols and road markings, whether they are sufficient in terms of safety. Going through the standards will further justify the present situation in terms of public safety and the accidents that may take place due to the present situation. The investigation shows that, there are some lacks at new airport road, while the condition of safety sign, symbols and road markings are well maintained at Mohakhali DOHS. In Mohammadpur, safety signs and symbols are way ahead than Uttara model town.
\end{abstract}

Keywords: Public safety, Signs symbols and road markings, Planned residential area, Highways, Accidents

\section{Introduction:}

Bangladesh is experiencing severe road safety problem and the situation has been deteriorating with increasing number of road accident deaths, largely as direct consequences of rapid growth in population, motorization, unplanned urbanization and lack of legitimate investment in road safety (Hoque, 2006). This paper tries to focus on the vulnerability of pedestrian and the vehicular movement in highway and the neighborhood area due to the lack of proper road safety sign, symbols and road markings.

In Thailand the road accidents involving pedestrians $(5.8 \%)$ are ranked third, following motorcycle (76.0\%) and pickup van (7.6\%) accidents (Hossain, 2006). In Bangladesh, road accident is costing nearly $2 \%$ of the GDP. (Hoque and Mullick, 2006). The solution of this problem is strictly location dependent, rather than universal. The road accidents are normally clustered in some specific sites, routes or locations. Specific treatments at such locations can greatly reduce the overall number of road accidents (Hoque and Mullick, 2006).

Around 4000 people die through road traffic accidents in our country every year. Dhaka city the most vulnerable road users are pedestrians and non motorized vehicle passengers who account for more than $80 \%$ fatalities (Hoque et al, 2006). Traffic accidents not only causes damage to property and to the vehicles but also kills human and brings about unthinkable sufferings and misery to the members of the victim's family. Pedestrians are by far the most vulnerable road users in Bangladesh. Pedestrians alone are involved in more than $47 \%$ of road accidents and $49 \%$ of all fatalities. In urban areas pedestrians accounted for $52 \%$ of fatalities and in Dhaka city this is nearly $70 \%$ (Hoque, 2006). Going through the following data which were telecasted in one of the satellite channels in Dhaka through news bulletin on $12^{\text {th }}$ of July 2011 the alarming situation regarding road accidents can easily be realized:

Each year 4000-5000 people die due to road accidents

Near about 10,000-12,000 people are injured due to road accidents each year

Each year more than 1,00,000 people who are the victims of road accidents goes under the line of poverty

$30 \%$ of the annual health budget are spent in the public hospitals, only for the people effected in different road accidents

Country's loss in economy is of $2 \%$ of the annual GDP due to road accidents

In Dhaka about $60 \%$ of trips are on foot while almost half of the remaining trips are on non-motorized vehicles (Mahmud, et al, 2006). Pedestrians, most vulnerable road user group is clear by data from police report showing that more than $48 \%$ of reported road accidents and $72 \%$ of reported fatalities were pedestrians in the 

context of Dhaka Metropolitan City (Mahmud, et al, 2006). Because of this huge amount of pedestrians involved in Dhaka city, focus should be given in terms of their safety in roads as well as in the neighborhoods.

Thus the objective of the study is to focus on the vulnerability of the pedestrian and the vehicular movement, respectively comparing different planned residential areas with adjacent highways of Dhaka city due to the lack of proper road safety sign, symbols and road markings that may result a range of casualties which are not at all desirable.

\section{Methodology:}

To carry out the study, visual and physical survey was done in one of the major highways of Dhaka city, which is the new airport road which leads to Uttara model town have been selected as heavy traffic flow can be observed in this road. Proper road safety sign, symbols and road markings are very much necessary for the safety of these fast moving vehicles along this road. While considering the residential neighborhood, the adjacent planned residential area of the new airport road, Uttara model town was selected. Three sectors of Uttara model town were selected randomly for the study due to time limitation and all the sectors were not possible to survey within the time. Walk down observation was carried out to compare the situation in other planned residential areas within the city i.e. Mohammadpur and Mohakhali DOHS were selected randomly to verify the situation of the signs, symbols and road markings regarding road safety.

\section{Standards:}

Standards are being followed all over the world regarding road safety sign and symbols. Traffic signs, control the flow of traffic, warn the hazards ahead, guide the destination, and inform the roadway services. Traffic signs are intentionally color coded to assist the operator.

RED - stop

GREEN - direction

YELLOW - general warning

BLACK/WHITE - regulation

BLUE - motorist service (e.g., gas, food, hotels)

BROWN - recreational, historic, or scenic site

ORANGE - construction or maintenance warning

\section{Stop And Yield Signs:}

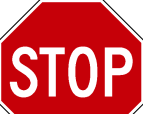

The STOP sign always means come to a complete halt and applies to each vehicle that comes to the sign. One must stop before any crosswalk or stop line painted on the pavement.

In case of YIELD sign, one has to slow down and be prepared to stop. Let traffic, pedestrians, or bicycles pass before he/she enters the intersection or join another roadway. He/she must come to a complete stop if traffic conditions require it.

\section{Regulatory Signs:}

The United States is now using an international system of traffic control signs that feature pictures and symbols rather than words. The red-and-white YIELD and DO NOT ENTER signs prohibit access or movement.

\section{Warning Signs:}

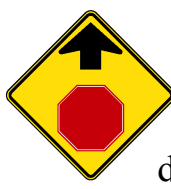

Yellow warning signs alerts one to hazards or changes in conditions ahead. Changes in road layout, proximity to a school zone, or some special situation are examples of warning signs. Slow down and obey the sign. Disregarding a warning sign is not only dangerous, it is against the law.

\section{Guide Signs:}

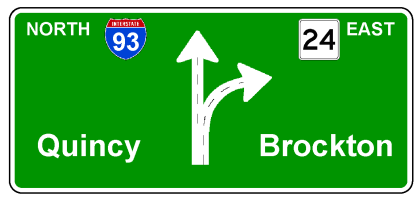

In the guide signs category one will find route markers, distance and destination signs, and informational signs. Green signs give highway directions and guide you through highway interchanges. 
Know traffic signs by their shapes:

Know signs by their appearances so you can recognize them at a distance.

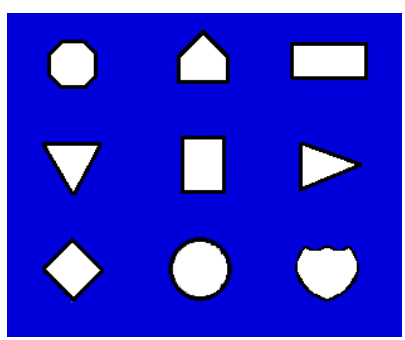

$\begin{array}{cll}\text { Stop } & \text { School Zone } & \text { Guide/Information } \\ \text { Yield } & \text { Regulation } & \text { No Passing Zone } \\ \text { Warning } & \text { Railroad Crossing } & \text { Interstate Highway }\end{array}$

Fig. Knowing traffic signs by their shapes

\section{Pavement markings:}

Lines, symbols, and words painted on a roadway help to direct riders and control traffic flow. One must know what the different lines and colors mean and obey them as one would traffic signs or signals. White and yellow lines are used along pavement edges and between lanes to keep vehicles in line. These lines may be solid or broken (long dashes), single or double. A solid white or solid yellow line that turns into a dotted line (short dashes) is a continuation of the line through an intersection or a highway interchange. Unless one is turning, exiting a highway, or changing lanes, always stay between the lines marking his/her lane.

(Source: www.mass.gov/rmv/dmanual/chapter4.pdf)

\section{Safety sign and symbols (local context):}

Bangladesh road transport authority (BRTA), classifies traffic and road signs into following categories:

Mandatory traffic signs

Mandatory signs

Warning signs

Information signs

Route signs

Road markings

Supplementary plates

The classification of the traffic signs by the BRTA are briefly described below:

\section{Mandatory traffic signs:}

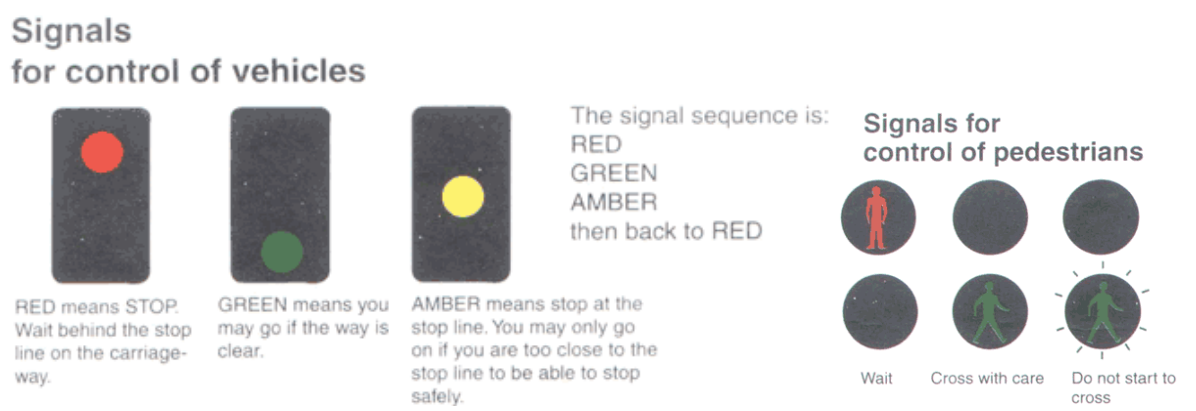

Mandatory signs:

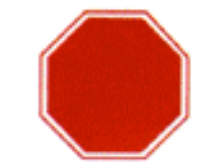

Stop and give way

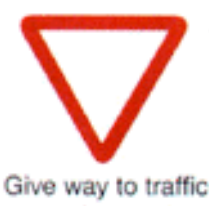

on major road or roundabout

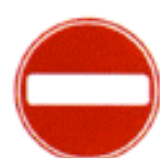

No entry for vehicles

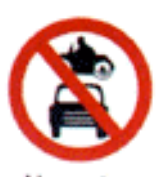

No motor

vehicles 


\section{Warning signs:}
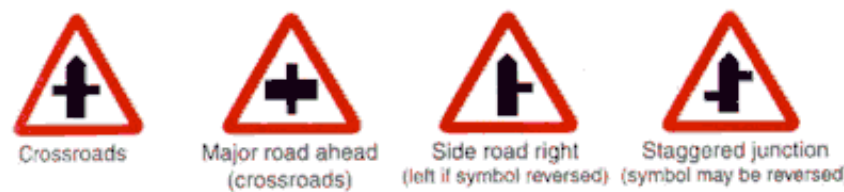

(ith if symbol reversedi) (symbol may be reversed)

Information signs:
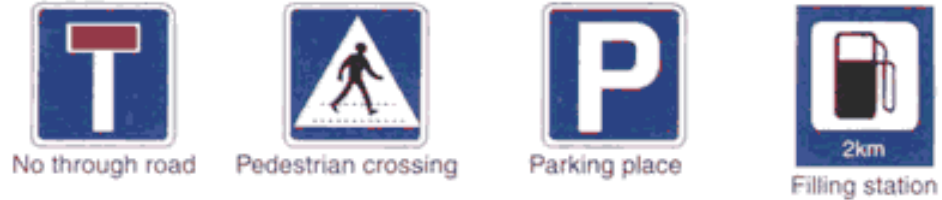

\section{Route signs:}

\section{Road markings:}
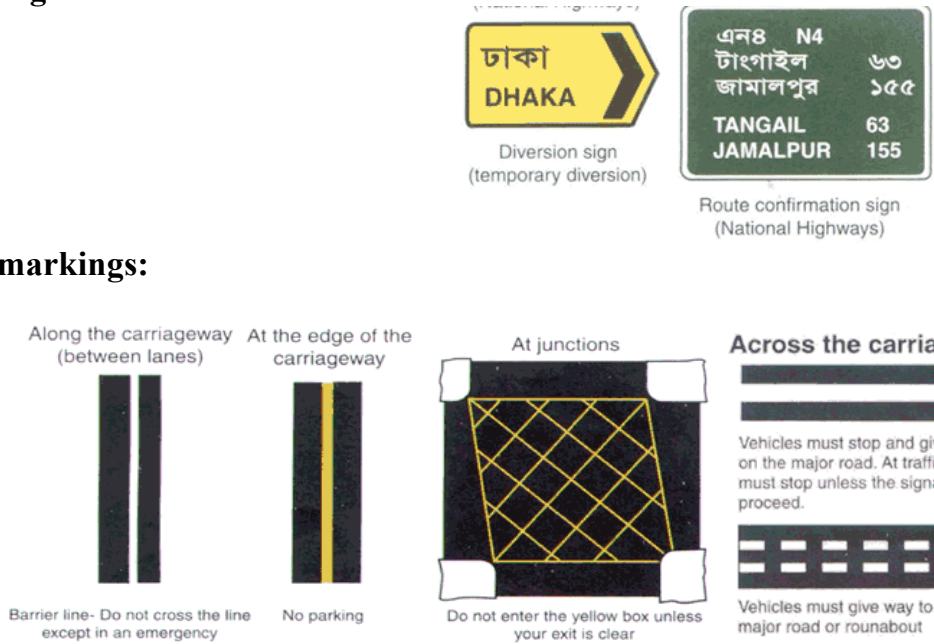

Across the carriageway

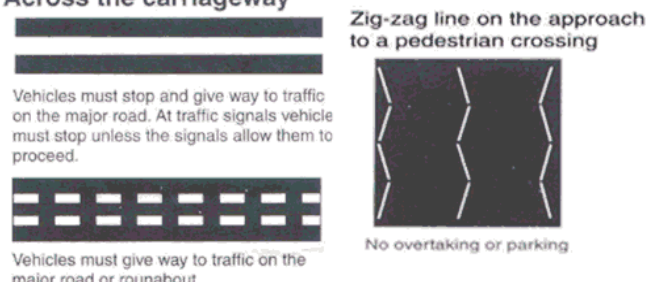

Supplementary plates:

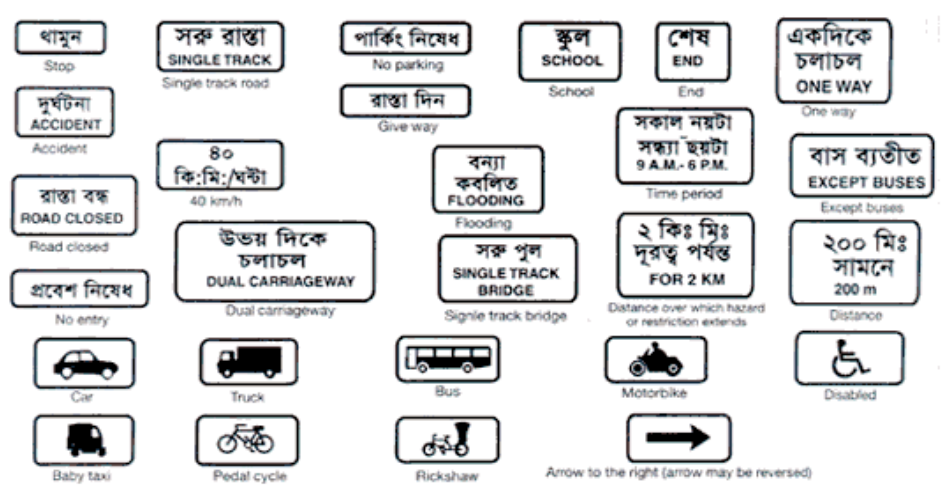

\section{Field Surveys:}

The present situation of sign symbols and road markings regarding public safety of the areas discussed above are described below.

\section{Case study 01: Airport road}

It has been observed that, being the airport a highway the parts connecting the adjacent towns of the road are very critical in terms of public safety. The traffic sign and symbols are not sufficient in terms of public safety, beside the ones, which are present, are not being obeyed properly by the mass people. So people are always at a risk. Some of the situations are seen in the figures (1-12). 

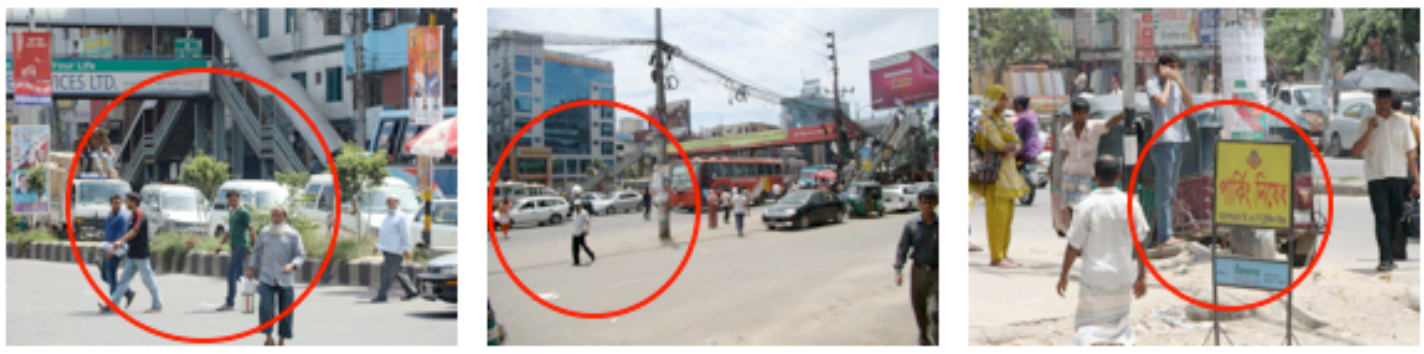

Fig.1 people not using foot over bridges for crossing the road

Fig.2 parking, in spite of 'no parking' sign
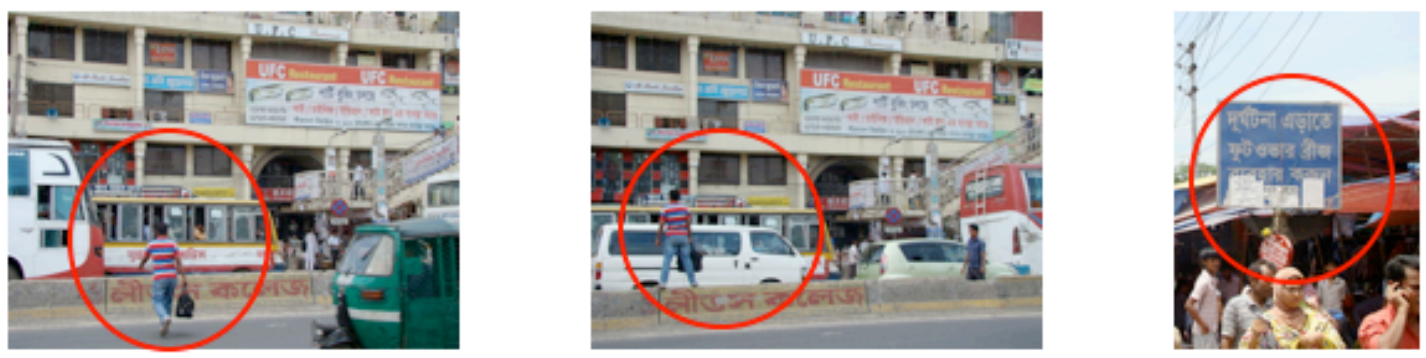

Fig.3 taking life risk for crossing the high way, standing on the road divider
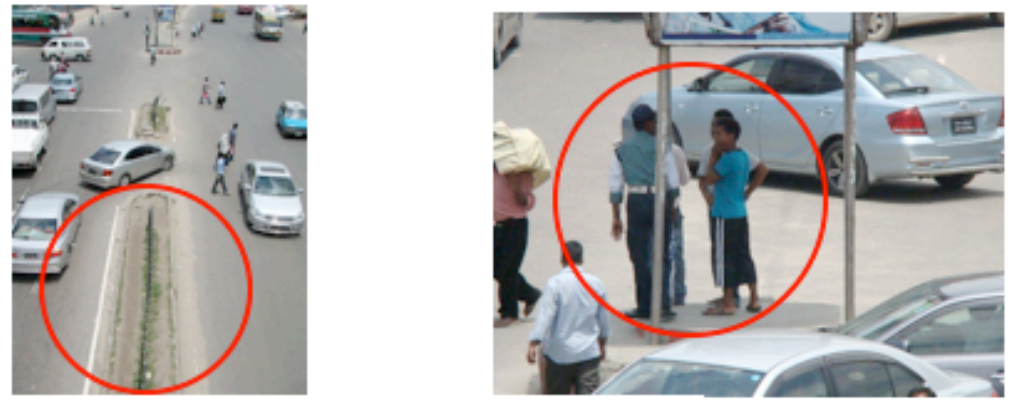

Fig.4 signboards used for posters

Fig.5 no 'U-turn signage and people crossing the road Fig.6 negligence of the duty causing chaotic node circulation

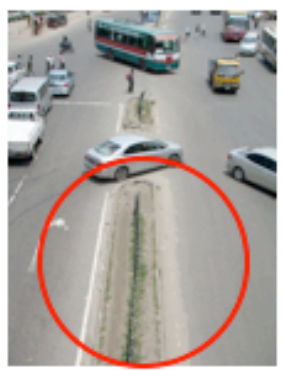

Fig.7 Road markings are very poor to read

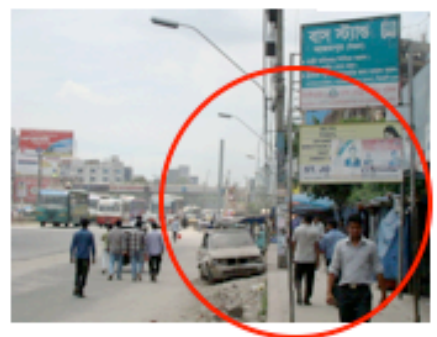

Fig. 10 place for bus stand but different garbage materials are kept

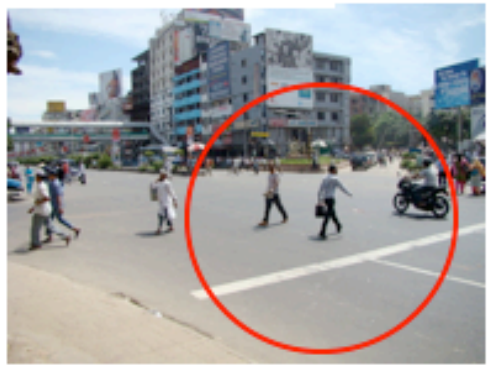

Fig.8 people are crossing the road, but no zebra crossing road marking available

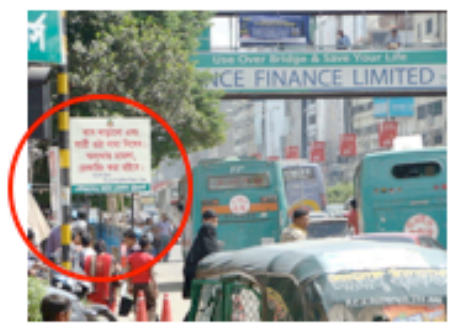

Fig.11 bus stops in spite of the 'no stop' instruction

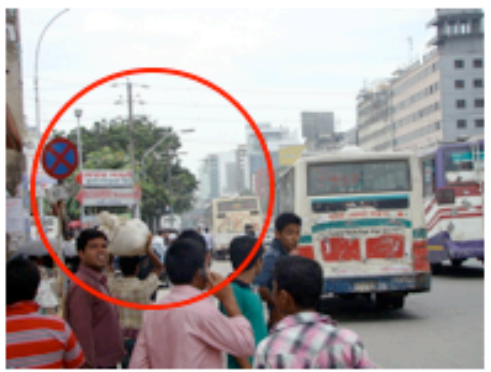

Fig. 9 the signage can hardly be seen

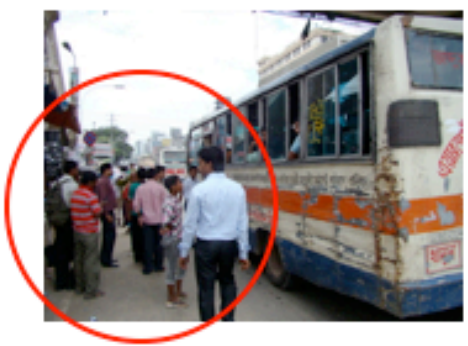

Fig. 12 people are standing on the road for bus taking their life risk 


\section{Case study 02: (Uttara model town, sector 07)}

Beside the general deficiencies of safety sign and symbols it has been observed that, there are three major functions in this sector for which this sector is quite renowned among other sectors and many people come here because of a big park, which is properly used by the residents of Uttara, a mosque and a large high school which serves the entire community. Despite all these important functions and huge number of people being using these, proper steps regarding safety sign and symbols are seen absent, which in turn are becoming risky for the users, especially for the children of the neighborhood. Below some pictures are shown to represent the situation. (Fig.13-21)

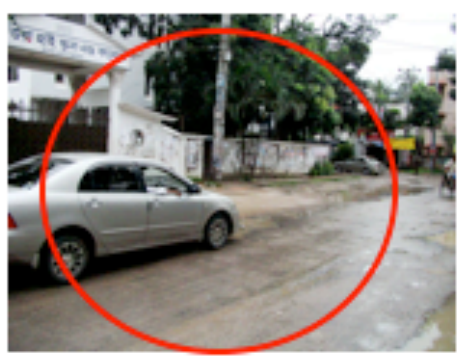

Fig.13 no safety measure in front of the school for children

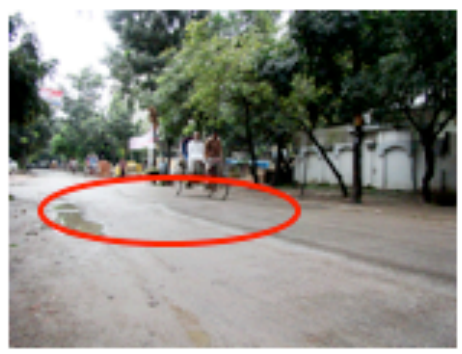

Fig.16 speed breakers can hardly be seen, which can cause accidents

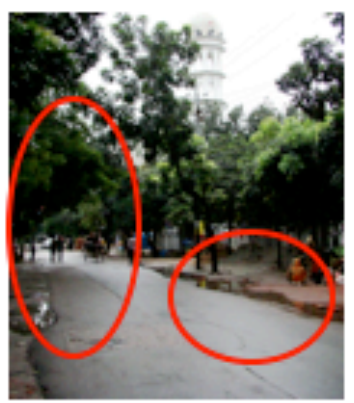

Fig.19 Mosque present, but road sign regarding mosque is absent

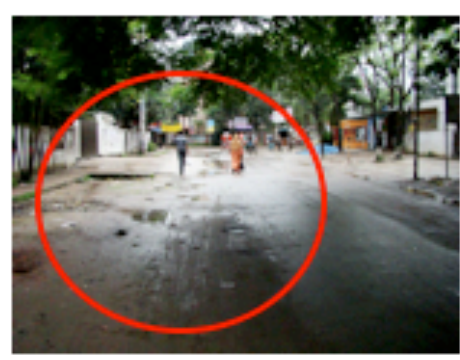

Fig.14 Using only central portion of a wide road

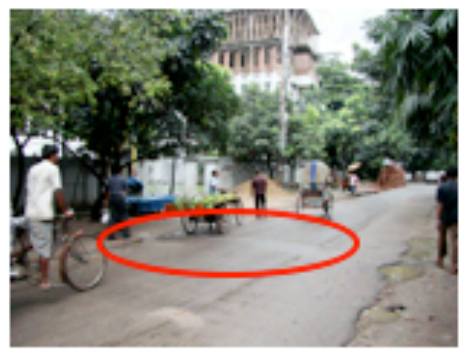

Fig.17 speed bumps can hardly be seen

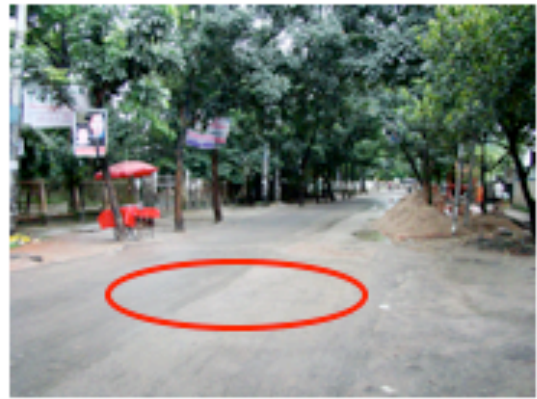

Fig. 20 speed bump in front of the park can hardly be seen and absence of proper signage regarding the park

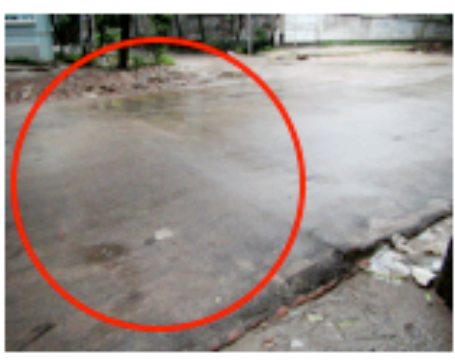

Fig.15 no marking on the speed breakers or speed bumps

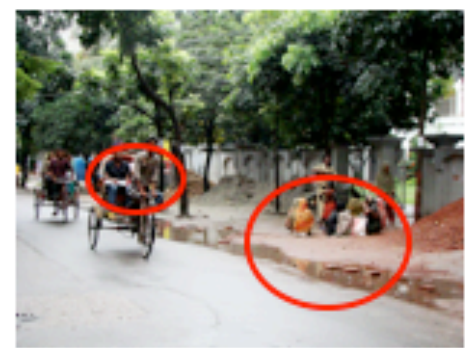

Fig. 18 construction materials here and there without any safety measures

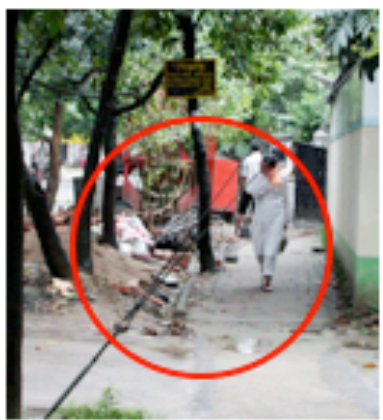

Fig.21 Situation of some paved areas are such that it is quiet hard to use them properly

Case study 03: (Uttara model town, sector 11)

Situation of sector 11 is quiet similar to the sector 7 seen above. Proper road marking, sign and symbols and required speed bumps are absent. (Fig.22-23) 

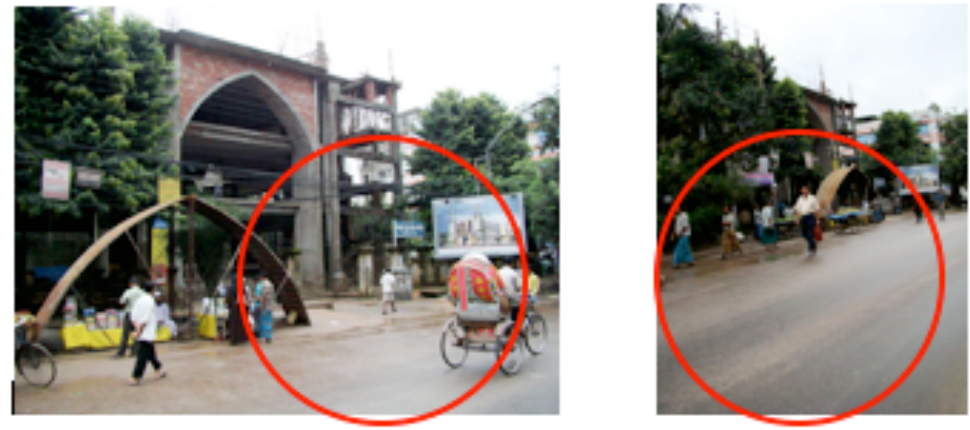

Fig.22 Absence of speed bump in front of the mosque, no road marking

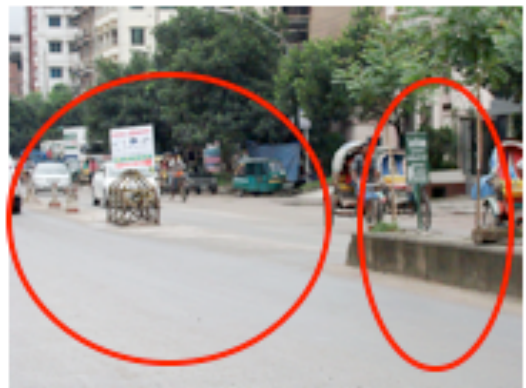

Fig.23 Absence of road marking along with no 'u-turn' signage

\section{Case study 04: (Uttara model town, sector 13)}

In case of sector 13 , no significant change could be seen in terms of safety measures regarding signs and symbols, in spite of there are major wide roads running through the sector for which the traffic flows within this zone is quiet high. The nodes are often busy with heavy traffic flow. As there are no traffic signals available, the circulations of the vehicles are governed by the traffic police, which in turns create traffic jams and increase the situation vulnerable. Road markings are also unavailable like the previous case studies. (Fig. 24)
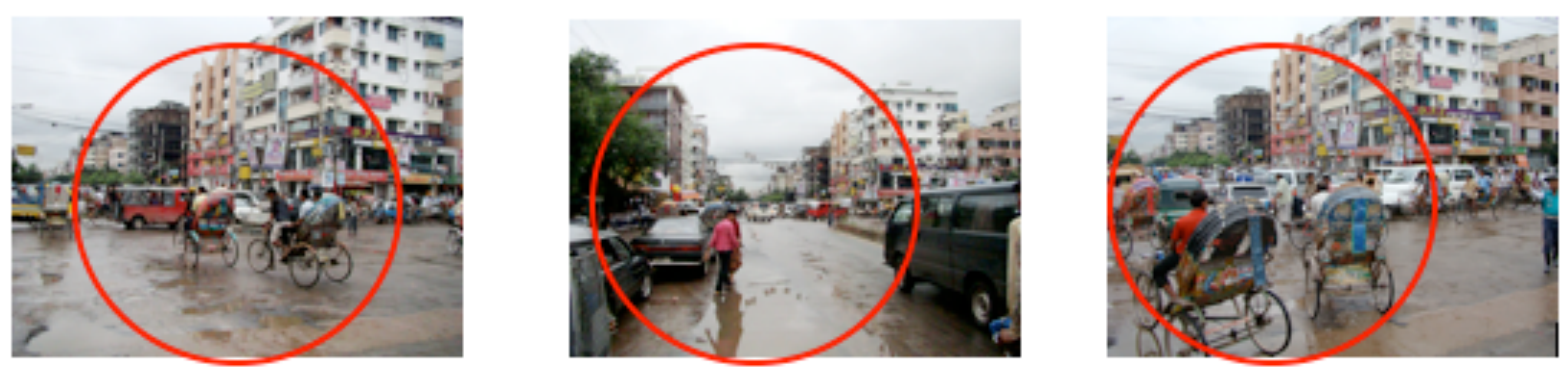

Fig.24 Absence of traffic signal, road markings and proper safety signage creates the node chaos and unsafe

\section{Case study 05: (Mohammadpur residential area)}

In case of Mohammadpur, the situation is quiet critical in terms of safety. The usage and the condition of the roads are critical as well. The bus stops, schools, mosques were studied to compare the situation with those of Uttara, but similar unsafe conditions were observed. Below the situation of Mohammadpur are presented through photographs. (Fig. 25-36)
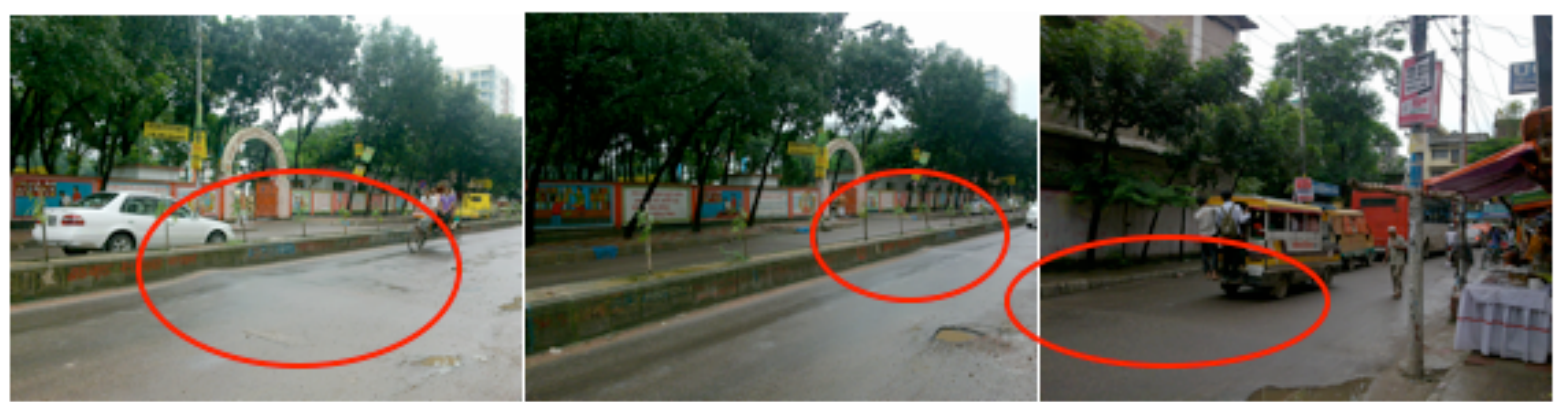

Fig. 25 speed breaker in front of school present but hardly can be seen, due to the absence of proper road marking (showing two different well known schools at Mohammadpur) 

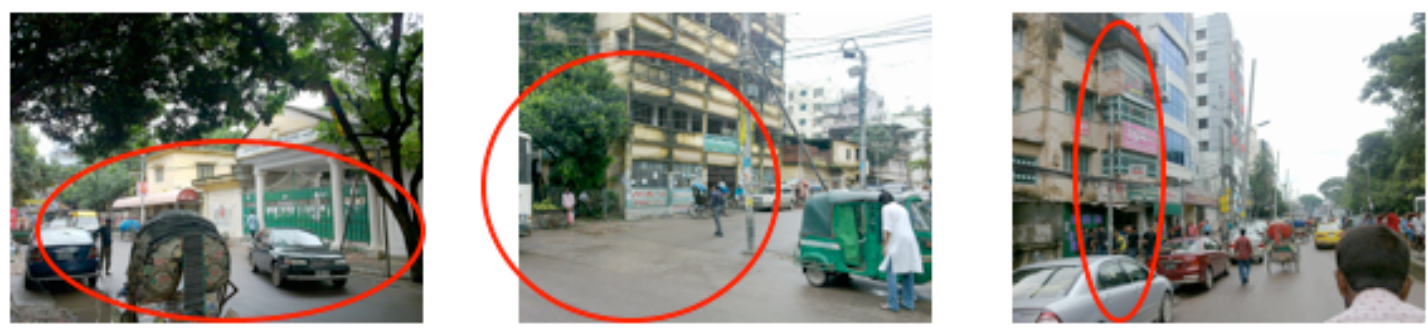

Fig.26 no signs and symbols provided in front schools (showing three different schools at Mohammadpur); the later two pictures also show the vulnerable condition of the school children have to face as the schools are just beside main roads, but no safety measures taken for the school going children

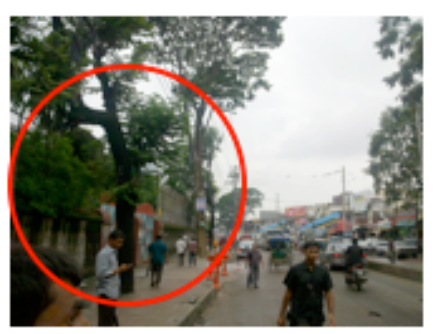

Fig. 27 Another renowned school at Mohammadpur having no proper signage
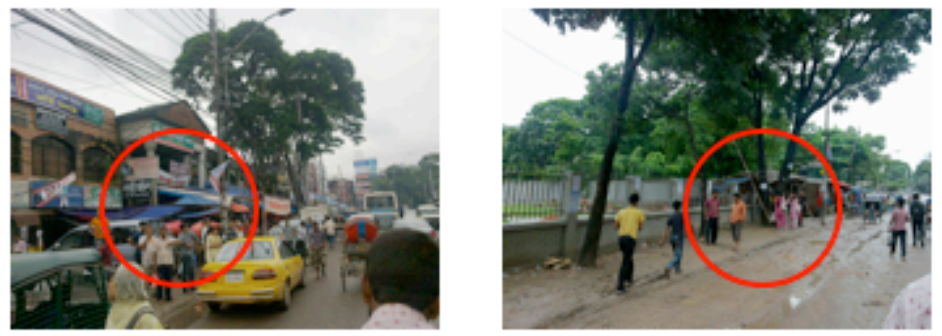

Fig.29 Two different bus stand showing in the picture - but hard to realize the bus stops due to the absence of signage and proper shading
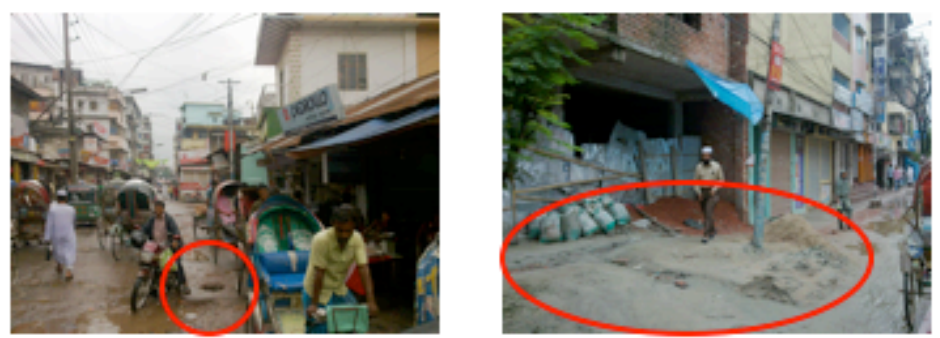

Fig.31 Poor condition of the roads and the placement of unauthorized construction materials on the roads creates public hazard. Obstruction in vehicular movement creates traffic clots within the neighborhood
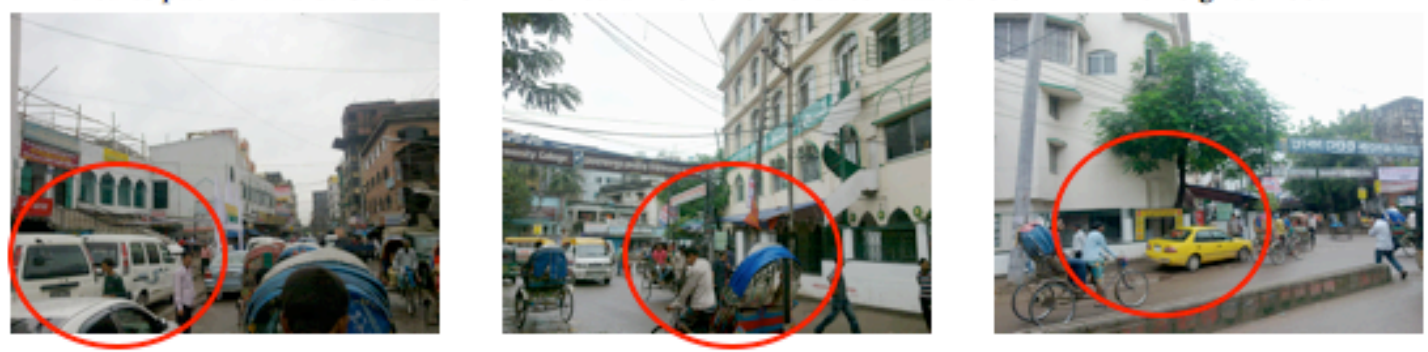

Fig.32 Above three pictures showing two different mosques of Mohanmadpur, having no such information through signage for the public. Similar situation can be observed in many other mosques at the locality 


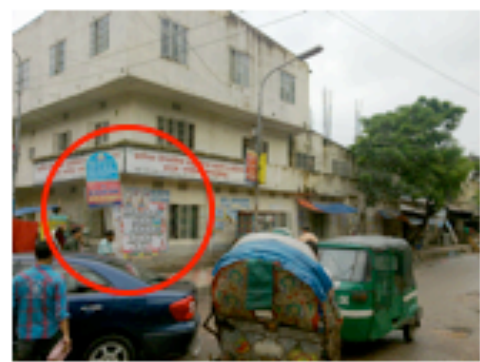

Fig.33 A madrasa showing in the picture with similar deficiency regarding signage. Other signage from police is present for the public, but in a very poor condition
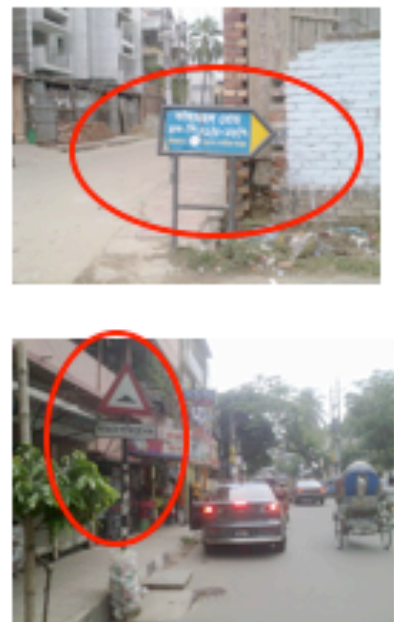

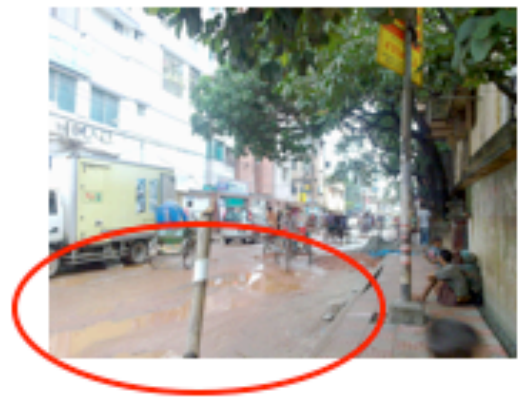

Fig.34 Road marking in this situation is out of the blue
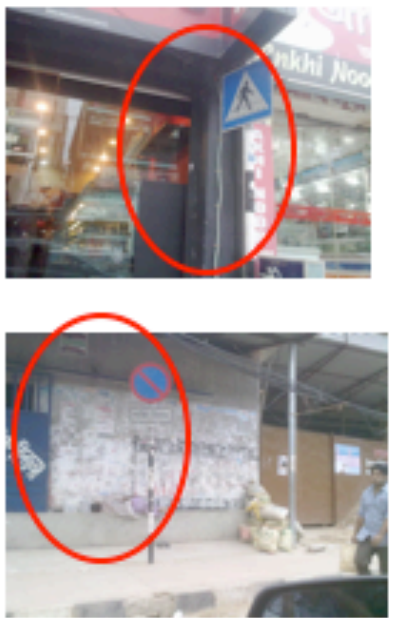

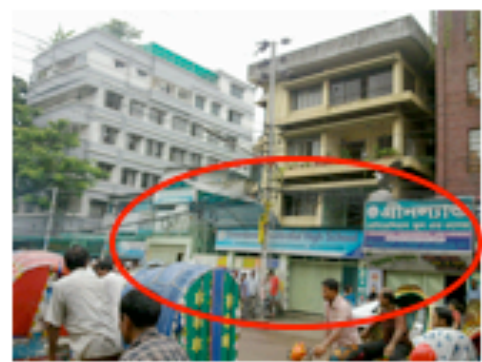

Fig.35 Schools beside heavy traffic road with no proper safety measures for the school going children are quiet vulnerable
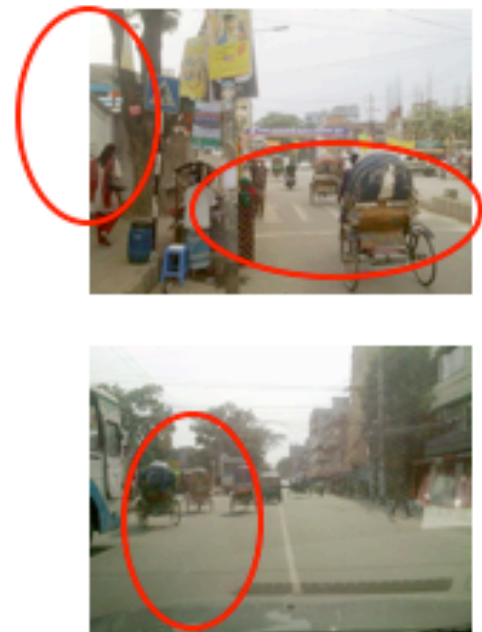

Fig.36 Different signage and road markings

\section{Case study 06: (Mohakhali DOHS)}

On the contrary, at Mohakhali DOHS the situation is better in terms of road safety signs and road markings. The following pictures are some samples of the situation. (Fig.37)
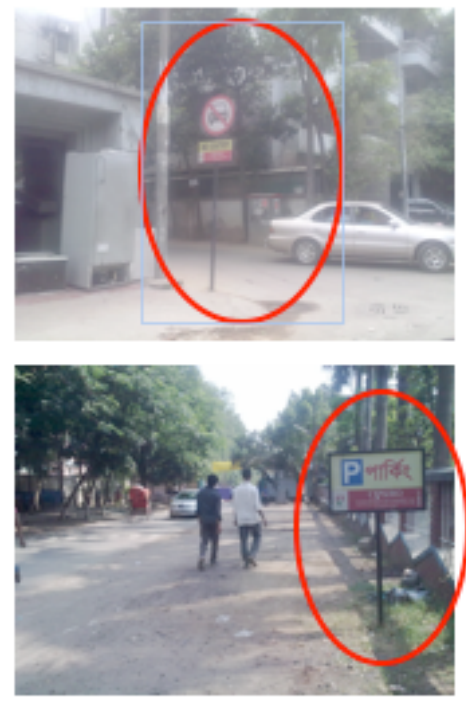
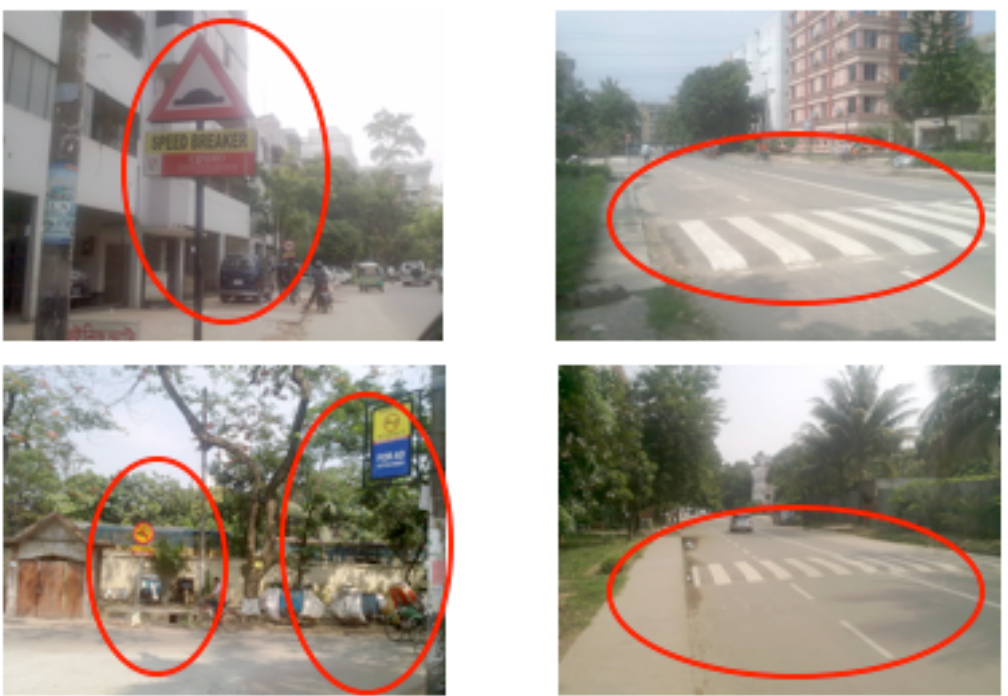

Fig.37 Road markings and road signs are visible clear and in good condition 


\section{Results And Discussion:}

Apart from airport road, on an average in each field surveys approximately twenty roads were surveyed (Uttara sectors 7, 11, 13; Mohammadpur and Mohakhali DOHS) were the number of signage in terms of mandatory signs, warning signs, information signs, route signs and road markings were observed and chart is made on the basis of these collected data, which is presented below to compare the scenario.

\begin{tabular}{|l|c|c|c|c|c|c|}
\cline { 2 - 7 } \multicolumn{1}{c|}{} & Airport rd. & $\begin{array}{c}\text { Sector } \\
07(\text { Ut.) }\end{array}$ & $\begin{array}{c}\text { Sector } \\
11(\text { Ut.) }\end{array}$ & $\begin{array}{c}\text { Sector } \\
13 \text { (Ut.) }\end{array}$ & M.DOHS & Md.pur \\
\hline Mandatory signs & 28 & 4 & 2 & 3 & 25 & 16 \\
\hline Warning signs & 25 & 2 & 3 & $*$ & 23 & 20 \\
\hline Information signs & 40 & 25 & 22 & 24 & 25 & 20 \\
\hline Route signs & 15 & 2 & 3 & 2 & 7 & 5 \\
\hline Road markings & 45 & 3 & $*$ & 2 & 26 & 24 \\
\hline
\end{tabular}

Table 1: Number of different signage at different spots of field survey

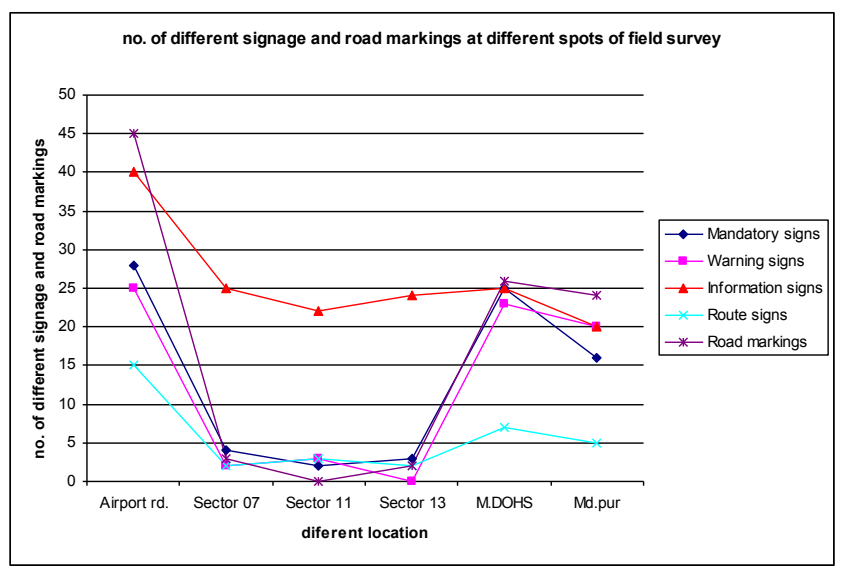

Fig.38: different signage and road markings at different spots of field survey

From the above table 1 and figure 38 it is quite clear that the condition of road safety signs and road markings are way ahead in Mohakhali DOHS and Mohammadpur; in Uttara other than information signs rests are way behind. The overall condition of the information signs is better than other signage in all the studied areas. The road markings of airport road are way ahead than other areas studied except Mohakhali DOHS. Within the airport road the condition of route sign is way behind than the rest signage. The overall signage condition at Mohammadpur is better than different surveyed sectors of Uttara.

So, proper signage and road markings are needed to be improved specially in different sectors of Uttara residential area in terms of mandatory, warning, route signs and road markings.

\section{Concluding Remarks:}

From the above discussion it is quiet clear that the current situation of road safety sign, symbols and road markings are insufficient in most areas in terms of pedestrians' safety. When it comes to adjacent highway the situation aggravates. Many zebra crossings are found on the roadways but the physical condition and visibility of them are very poor due to poor or no road markings at all. This situation fails the attention of the motor drivers for safer pedestrian crossing. In order to minimize delay, the motor drivers have a tendency to cross the junctions quickly. The uses of foot over bridges are seldom, unless bound to do so (when the roads are barricaded with road dividers). Few designated places for the bus stoppage were found, which results the buses to stop in road side causing traffic jam and also creates risks in pedestrian movement. Most of the busses stop in road side haphazardly and boards passengers dangerously. This makes always crowed on road side and influence pedestrian to move on road. Proper signage is absent in the neighborhoods for the safety of the pedestrians. Schools, mosques, bazaars, bus stops all are signage free for which pedestrian movement within the locality, let alone by the major roads are pretty vulnerable.

Designated bus stoppage with proper designed layout at appropriate place should be provided and the attitude of back and forth bust stop as well as boarding and unloading of the passengers must be controlled. Appropriate and sufficient usage of signage must be adopted for the safety of the pedestrians. Unplanned use of various functions within the locality, risks the mobility of the pedestrians. This must be taken into account also for their safety.

The overall safety requirements are inadequate in terms of public safety (pedestrians as well as for the drivers) in planned residential neighborhood and the adjacent highways. There are many scopes for road and 
neighborhood environment to improve in terms of safety sign, symbols and road markings to reduce the possibilities of pedestrian accidents. If proper steps are not taken with a view to the safety of pedestrians and also for the drivers, road accidents would be unfortunate outcome.

\section{References:}

[1]. Hossain M. (2006), A Study on Pedestrian Accidents Based on the Injury Surveillance (IS) Data: Thailand's case, Proceedings of international conference on Road Safety in Developing Countries. Accident Research Centre (ARC), BUET

[2]. Hoque M.M., Debnath P., Alam M.D., Ahmed S.N. (2006), Metropolitan Street Accidents: The Case of Dhaka, Proceedings of international conference on Road Safety in Developing Countries. Accident Research Centre (ARC), BUET

[3]. Hoque M.M. (2006), Road Safety in Bangladesh: The Contemporary Issues and Priorities, Proceedings of international conference on Road Safety in Developing Countries. Accident Research Centre (ARC), BUET

[4]. Mahmud S.M.S., Hoque S., Hossain M.M., Hoque M.M., (2006), Pedestrian Safety Problem, Existing Facilities and Required Strategies in the context of Dhaka Metropolitan City, Proceedings of international conference on Road Safety in Developing Countries. Accident Research Centre (ARC), BUET

[5]. Hoque A., Mullick R.A., (2006), Two Hazardous Road Locations In Chittagong City and Some Possible Counter Measures, Proceedings of international conference on Road Safety in Developing Countries. Accident Research Centre (ARC), BUET

[6]. Massachusetts, 2012. Registry of Motor Vehicles. www.mass.gov/rmv/dmanual/chapter4.pdf (accessed on 2012) 